\title{
Comparison of Sugar and Honey Dressings in Healing of Chronic Wounds
}

\author{
${ }^{1}$ Dr Rahul R Bhat , ${ }^{2}$ Dr Manohar V Pai* ${ }^{3}$ Dr Shankar Ram Hs, \\ ${ }^{4}$ Dr Sandeep Reddy, ${ }^{5}$ Dr Shivaprasad Rai , ${ }^{6}$ Dr Poornachandra Thejeswi, \\ ${ }^{7}$ Dr Shivananda Prabhu \\ ${ }^{I}$ Assistant Professor Department of General Surgery KMC Mangalore Manipal University \\ ${ }^{2}$ Associate Professor Department of General Surgery KMC Mangalore Manipal University \\ ${ }^{3,4}$ Resident Department of General surgery KMC Mangalore Manipal University \\ ${ }^{5}$ Professor Department of Surgery KMC Mangalore Manipal University \\ ${ }^{6}$ Associate Professor Department of Surgery KMC Mangalore. Manipal University \\ ${ }^{7}$ Professor and Unit Chief Department of Surgery KMC Mangalore Manipal University
}

\begin{abstract}
Honey and Sugar dressings were applied to long standing surgical wounds in two groups comprising 25 patients in each matched for age and comorbidities.Dressings were done once in 3 days .Patients in sugar dressing group had faster healing rate, shorter hospital stay with rapid slough and microbial clearance. Sugar dressing also proved to be cost effective with decreased debridement frequency at the end of the study.
\end{abstract}

Key Words: Sugar dressing ,Honey dressing ,chronic surgical Wounds.

\section{Introduction}

Healing of ulcers is a serious problem but preventing recurrence is a greater challenge. For this, patients stay longer duration in the hospital which is costly and financial burden for the family. But with the study intended we are looking for a better treatment and to look for the faster healing rates and thereby reduce longer stay and more cost effective with better results.

Honey is one of the oldest foods in existence and was an ancient remedy for wound healing. Honey has a number of properties that make it effective against bacterial growth, including its high sugar content, low moisture content, gluconic acid which creates an acidic environment and hydrogen peroxide. Researchers have also reported that applying honey can be used to reduce amputation rates among diabetes patients ${ }^{1}$.

Dunfard and Hanano studied the acceptability of honey dressing in patients with non healing leg ulcers, particularly in terms of pain reduction, odour control and general patient satisfaction. Amongst the 40 patients recruited, $20(50 \%)$ reported a decrease in pain levels, 20 out of 21 patients also reported decrease in odour due to use of honey ${ }^{2}$. He has shown scientifically that most honey have a varying degrees of healing properties due to a naturally occurring hydrogen peroxide agent. He found that when honey comes into contact with body moisture the glucose oxidase enzyme introduced to the honey by the bee, slowly releases the antiseptic hydrogen peroxide ${ }^{3}$. This is released at sufficient levels to be effective against bacteria but not tissue damaging.

The use of finely powdered sugar to clean wounds was reported by Scultetus in 1679 but the mechanism of action was not elucidated until the twentieth century. Sugar therapy is suitable for treating patients with degloving injuries, infected surgical wounds, necrotizing fasciitis, decubitus ulcers, burns and others that require a healthy granulating bed to heal. No adverse effects have been reported with the use of sugar $^{4}$.

When used as a dressing for wounds, sugar facilitates the formation of a protective layer of protein on the wound and has antibacterial properties due to its osmotic action. Sugar dressings reduce the need for surgical debridement because sugar draws macrophages to the wound which cleanse the wound and accelerates sloughing of devitalized tissue. Sugar treatment provides a local nutrient source, decreases inflammatory edema and enhances sterilization of the wound, resulting in enhanced granulation and epithelialization ${ }^{5}$.

Composition of Sugar paste

\begin{tabular}{|l|l|l|}
\hline Ingredients & Thin & Thick \\
\hline Caster Sugar & $1200 \mathrm{gm}$ & $1200 \mathrm{gm}$ \\
\hline Icing Sugar & $1800 \mathrm{gm}$ & $1800 \mathrm{gm}$ \\
\hline Polyethylene glycol & $1416 \mathrm{ml}$ & $686 \mathrm{ml}$ \\
\hline Hydrogen peroxide 30\% & $23.1 \mathrm{ml}$ & $19.0 \mathrm{ml}$ \\
\hline
\end{tabular}

A chronic wound is a wound that does not heal in an orderly set of stages and in a predictable amount of time the way most wounds do; wounds that do not heal within three months are often considered chronic ${ }^{6}$. 
Chronic wounds seem to be detained in one or more of the phases of wound healing. For example, chronic wounds often remain in the inflammatory stage for too long. In acute wounds, there is a precise balance between production and degradation of molecules such as collagen; in chronic wounds this balance is lost and degradation plays too large a role.

Chronic wounds may never heal or may take years to do so. These wounds cause patients severe emotional and physical stress as well as creating a significant financial burden on patients and the whole healthcare system. Acute and chronic wounds are at opposite ends of a spectrum of wound healing types that progress toward being healed at different rates.

\section{Materials And Methods}

Honey and Sugar dressings were applied to long standing chronic wounds, wounds that require prolongedwound care / hospitalization or delayed healing is anticipated.Healing rates were studied after application of either sugar or honey dressing. Only sterile honey and sugar pastes were used for ulcers. Dressings were done once in 3 days in all the patients. The honey and sugar paste were subjected to weekly analysis for culture over the period of study and was discarded if culture grew any organisms. Subsequently new dressing material was used. Prospective study of patients included 25 cases each for honey and sugar dressings. Patients who had long standing chronic ulcers like diabetic ulcers, venous ulcers, pressure ulcers (with slough, contamination, edema and foul smell).Acute wounds like burns, abrasions, lacerations, clean and granulated ulcers ,Peripheral vascular disease were excluded in our study. The etiology, dressing frequency, debridement frequency rates were studied. Wound surface area was calculated by Photographic method ${ }^{7}$.Pain was assessed by Visual Analogue scale after saline wash of the wound and after application of either sugar paste or honey. The change of score was noted as delta VAS for each dressing. SPSS 15 was used for statistical analysis and $\mathrm{p}<0.05$ was considered significant. The study is in accordance with standards of Declaration of Helsinki and Ethics committe approval was obtained.

\section{Observations And Results}

The mean age of study population was 57.4 SD 8.4 in the sugar group and 60.6 SD 7.88 yrs (p $=.208$ ). The mean duration of the study in the patients in both the groups were 5.8 wks SD 3.2 and 6.2 wks SD 5.3. Out of 25 sugar dressings [ 12 were diabetic, 7 were venous \& 6 were pressure sores].Out of 25 honey dressings [10 were diabetics, 10 were venous \& 5 were pressure sores].Malignant wounds were excluded from study .The distribution of nature of wound in both groups is mentioned in the Figure 1.

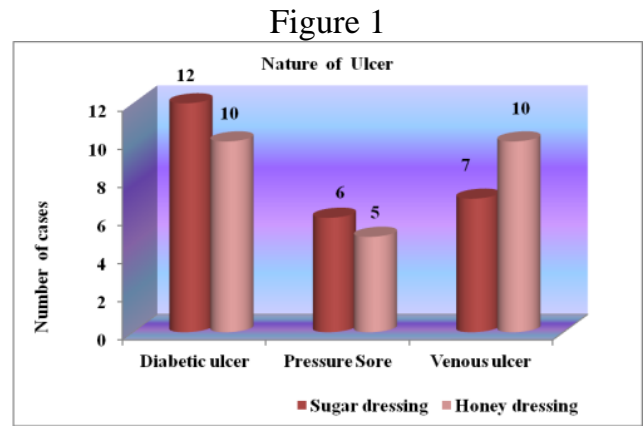

The frequency of Debridements in both the groups are picturised in Figure 2. In the sugar dressing group 6 patients required once and 3 required twice making a total of 12 debridements. In honey dressing group there were 18 debridements for the same number of study population. There were no significant side effects in either of the groups that could be attributed to the dressing.

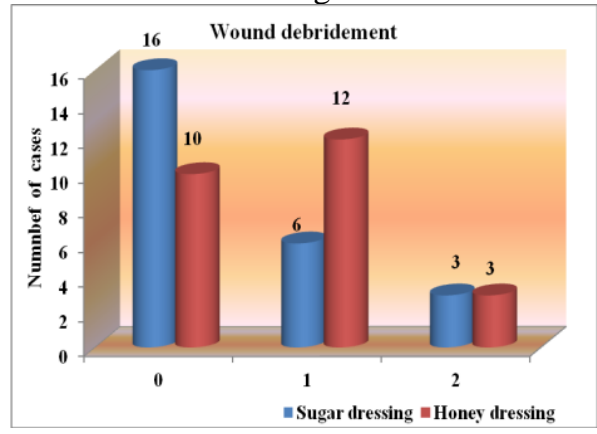


Fiigure 2 .The $\mathrm{x}$ axis shows the number of debridements done in each group from the time of admission and $\mathrm{y}$ axis shows the number of cases .

Wound Healing

\begin{tabular}{|c|c|c|c|}
\hline Characteristic & $\begin{array}{l}\text { Sugar Dressing } \\
\mathrm{N}(25)\end{array}$ & Honey dressing N (25) & Significance \\
\hline Slough clearance & 8.4 SD 4.2 days & 15.2 SD 5.1 days & $\mathrm{S}$ \\
\hline Mean Microbial clearance & $\begin{array}{l}62 \text { centile of inpatient } \\
\text { days }\end{array}$ & $\begin{array}{l}73 \text { centile of inpatient } \\
\text { days }\end{array}$ & $\mathrm{S}$ \\
\hline $\begin{array}{l}\text { Mean Wound Healing } \\
\text { rate. } \\
\text { Max wound size taken as } \\
100 \text { centile during the } \\
\text { hospital stay. }\end{array}$ & $\begin{array}{l}\text { 6.9 SD } 2.9 \text { Percentile } \\
\text { /wk }\end{array}$ & $\begin{array}{l}5.1 \text { SD } 2.4 \\
\text { Percentile /week }\end{array}$ & $\mathrm{S}$ \\
\hline $\begin{array}{l}\text { Mean Duration of } \\
\text { Healing( From admission } \\
\text { to primary closure /SSG)/ } \\
\text { Flaps }\end{array}$ & 30 SD 6 days & 43 SD 8 days & $\mathrm{S}$ \\
\hline Mean Initial Wound size & $89.5 \mathrm{sqcm}$ SD 20.1 & $94.1 \mathrm{sq} \mathrm{cm} \mathrm{SD} 18.3$ & NS \\
\hline $\begin{array}{l}\text { Cost ratio (Dressing and } \\
\text { inpatient charges ) }\end{array}$ & 1 & 1.4 & $\mathrm{P}<0.01$ \\
\hline $\begin{array}{l}\text { HbA1C } \\
\text { At admission }\end{array}$ & $\begin{array}{l}\mathrm{N} 12 \\
8.3 \mathrm{SD} 1.1\end{array}$ & $\begin{array}{l}\text { N } 10 \\
7.9 \text { SD } 1.3\end{array}$ & NS \\
\hline $\begin{array}{l}\text { HbA1C } \\
\text { At end of study and } 3 \\
\text { months follwup. }\end{array}$ & $\begin{array}{l}\text { N } 12 \\
7.1 \text { SD } 0.9\end{array}$ & $\begin{array}{l}\mathrm{N} 10 \\
7 \text { SD } 1.2\end{array}$ & NS \\
\hline Pain Delta VAS & 1.3 (mean) & 0.9 (mean $)$ & NS \\
\hline
\end{tabular}

Table 1 shows characteristics of Healing in groups of sugar and honey dressing

\section{Discussion}

Individual studies have shown very good healing rates on chronic ulcers compared to conventional treatment. Sugar and Honey have themselves a lot of healing properties by the nature of contents they have. In this study we tried to compare the healing process between the two methods of dressings .

After the initial debridement both sugar and honey dressings were applied to the wounds. The groups were comparable in terms of age , number, comorbidity profile and wound size . The Results \& characteristics of the Wound Healing are shown in Table 1.There was a significantly better healing with sugar dressing in terms of reduced duration of hospital stay, rapid desloughing rate, and microbial clearance. Though making sugar paste was little expensive than purchasing Honey Sugar dressing worked out economical on the long run. The sugar paste was made separately for each patient were stored in sterile plastie containers or sachets were used for 3 months. When duration of hospital stay ,number of debridements and dressings were audited for cost ,sugar dressing was preferable. The Pictures of the Wounds healing with Sugar dressing is shown below.

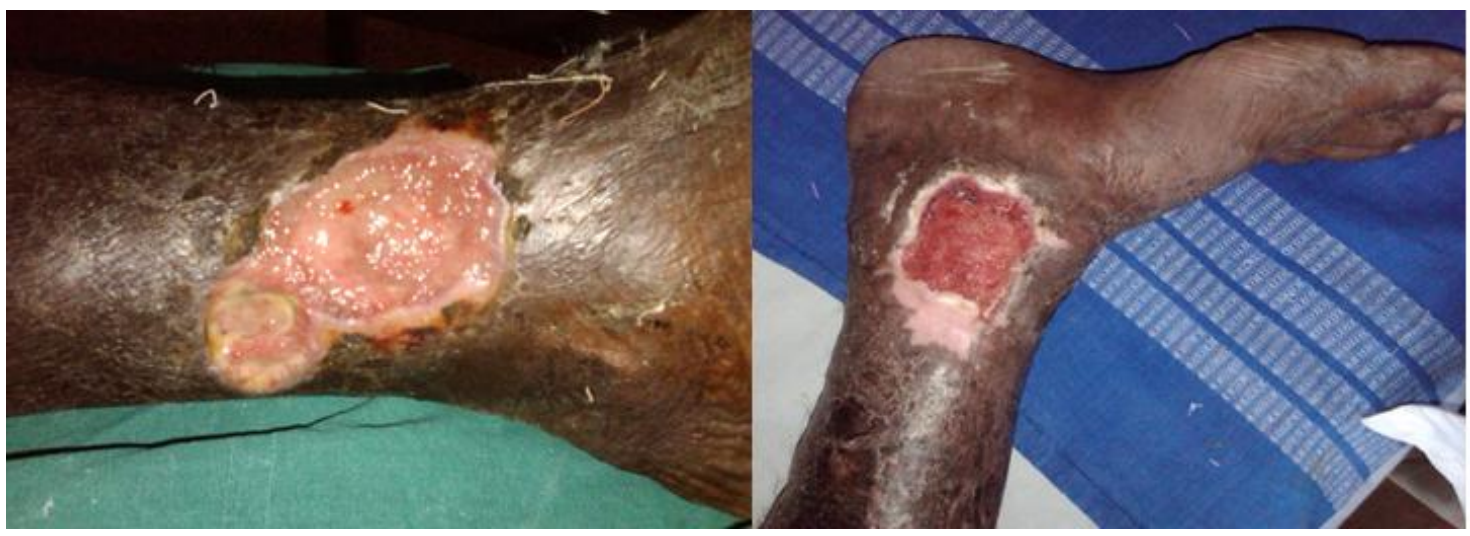

Figure 3 . Venous Ulcer Healed with sugar dressing 

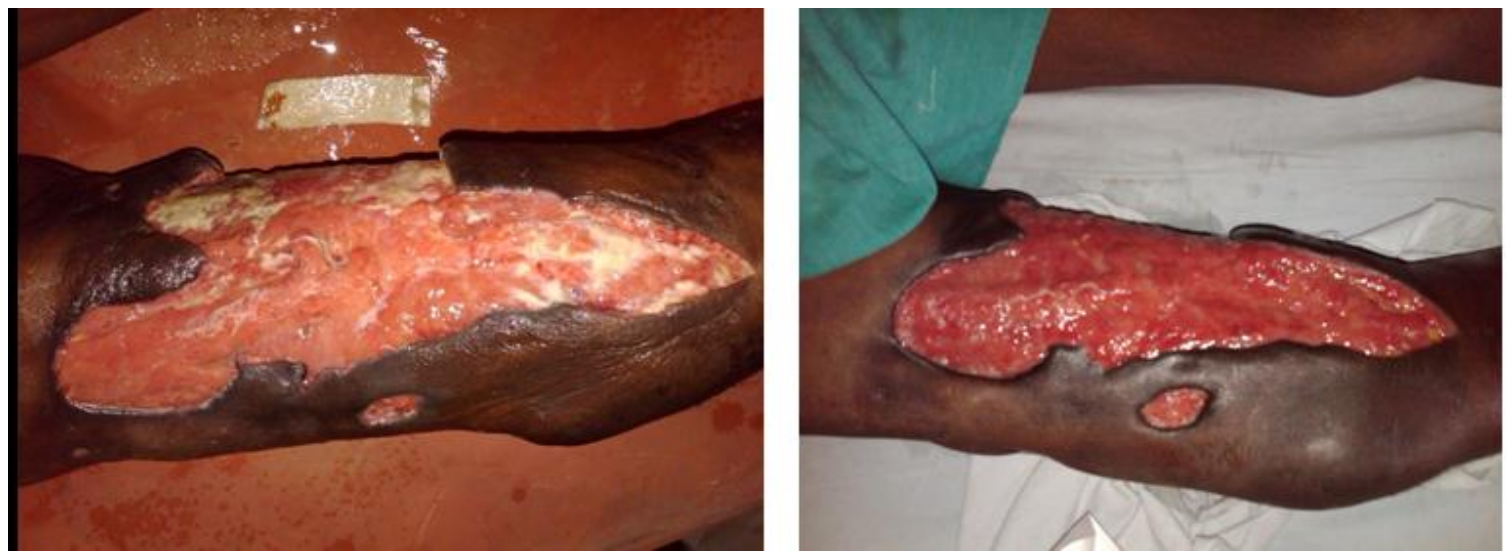

Figure 4 . Necrotising Fascitis of the Thigh Desloughed with serial sugar sugar dressing
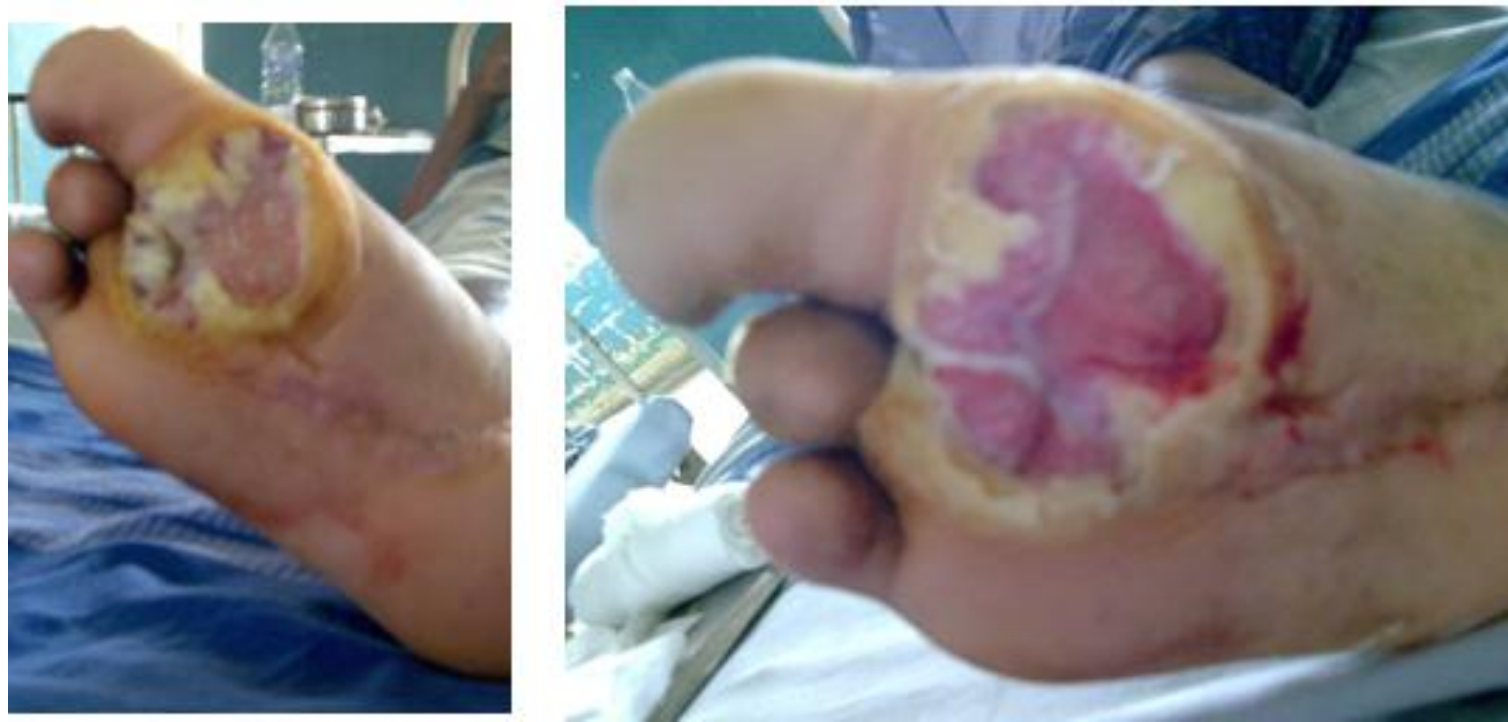

Figure 5 .Pressure sore of the foot healed with sugar dressing

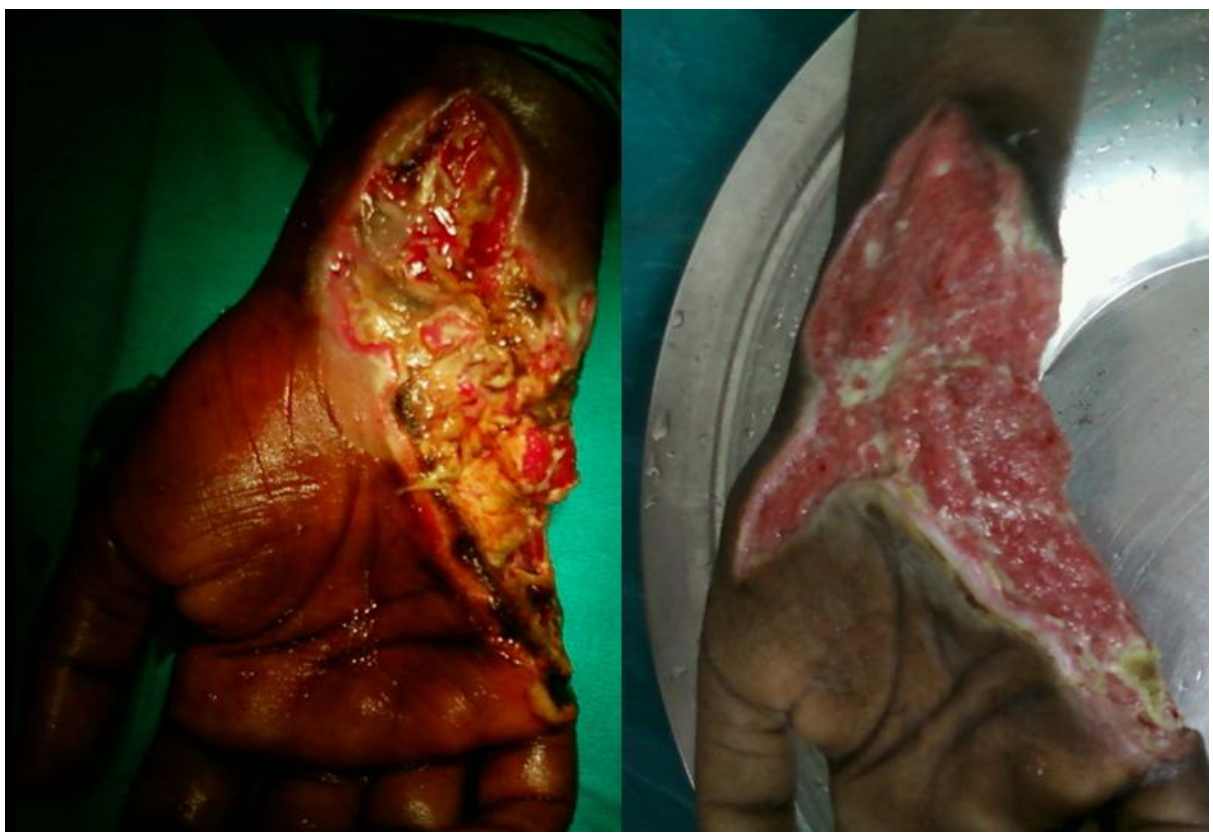

Figure 6 .Necrotising fascitis of the hand treated with sugar dressing 

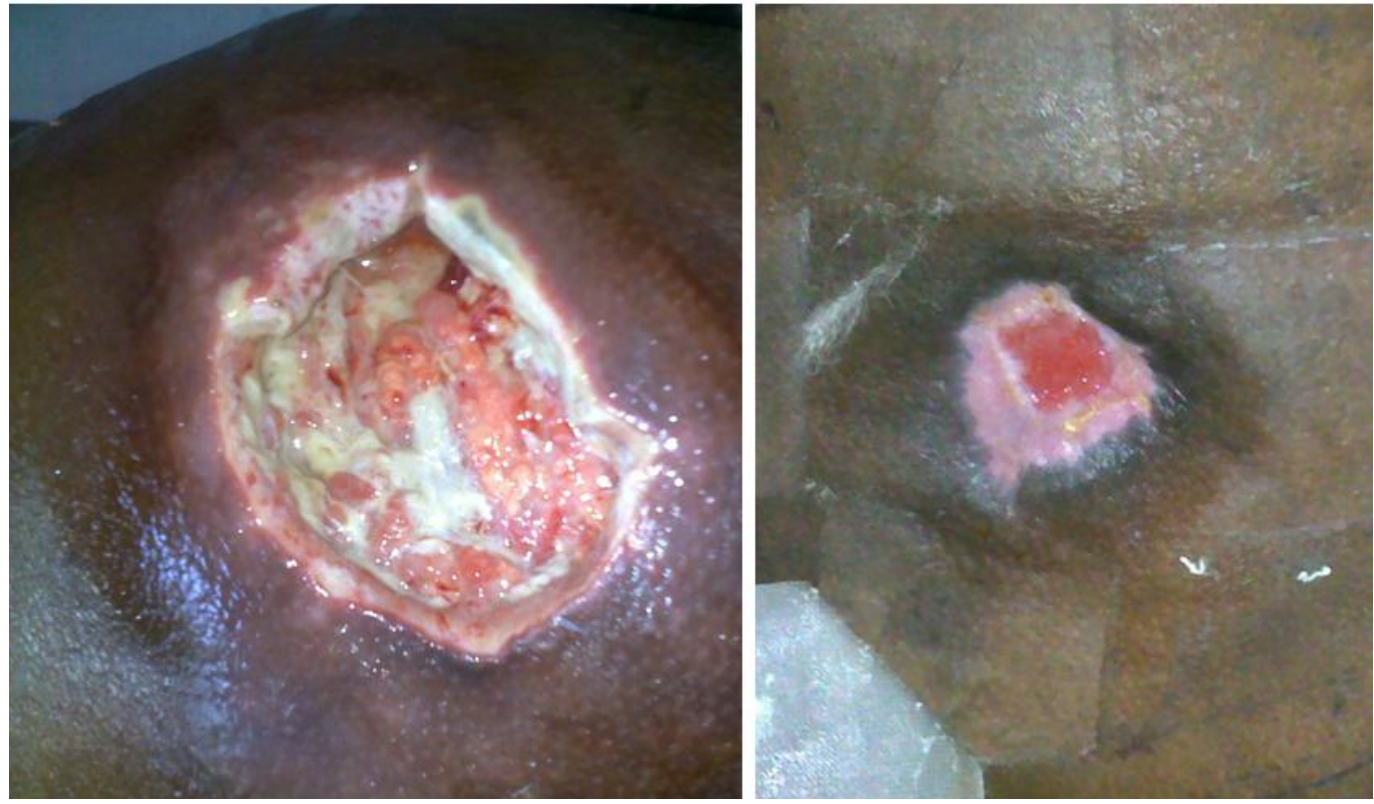

Figure 7 .Debrided Pressure sore healed with Sugar Dressing
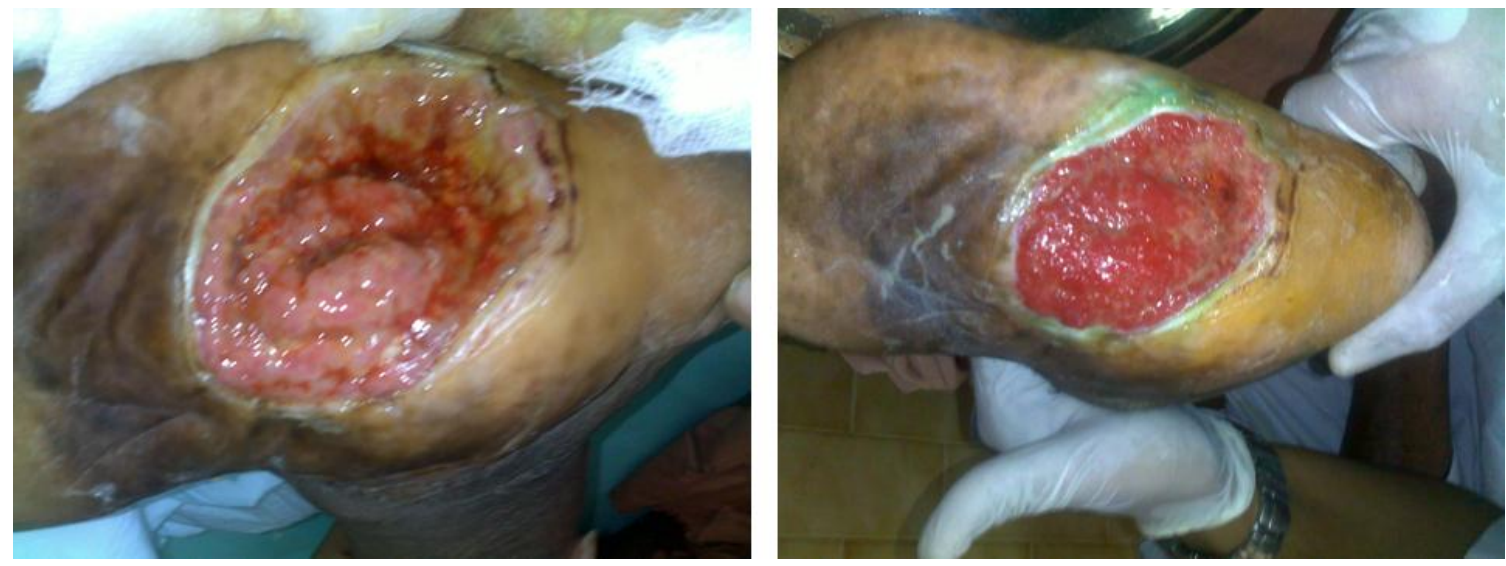

Figure 8.Plantar Ulcer Healed with Sugar Paste

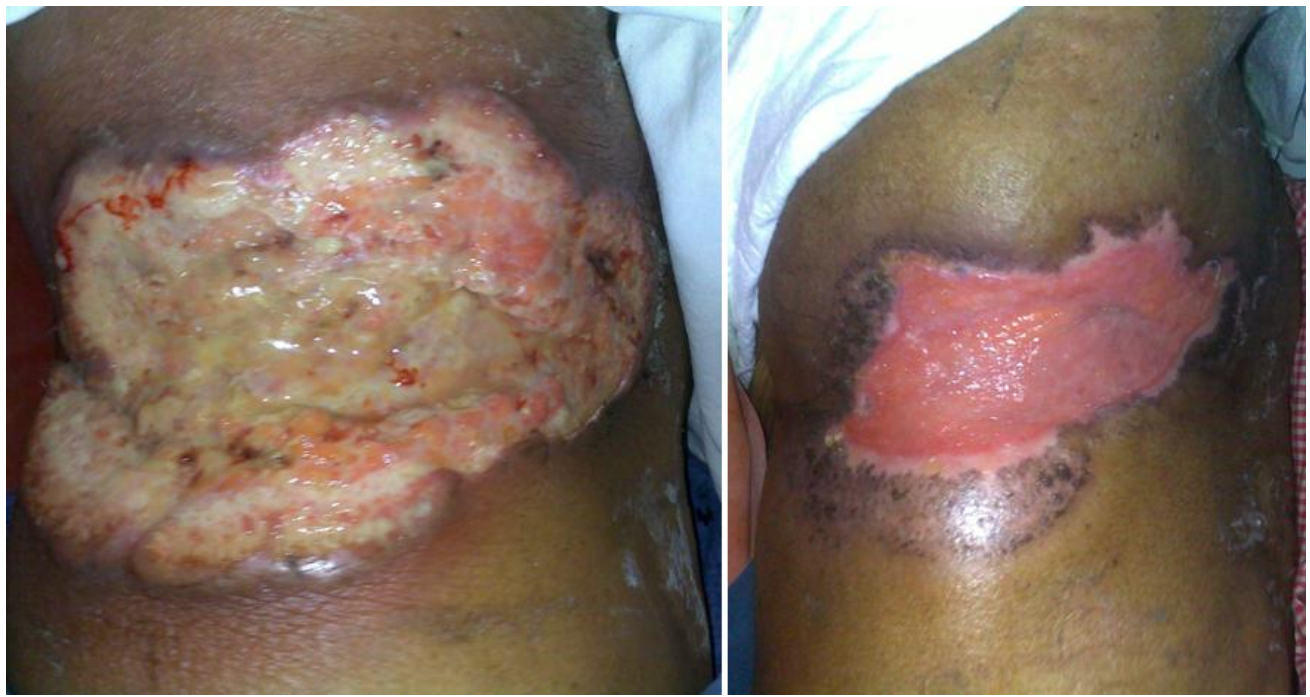

Figure 9. Loin Ulcer healed with sugar dressing. 


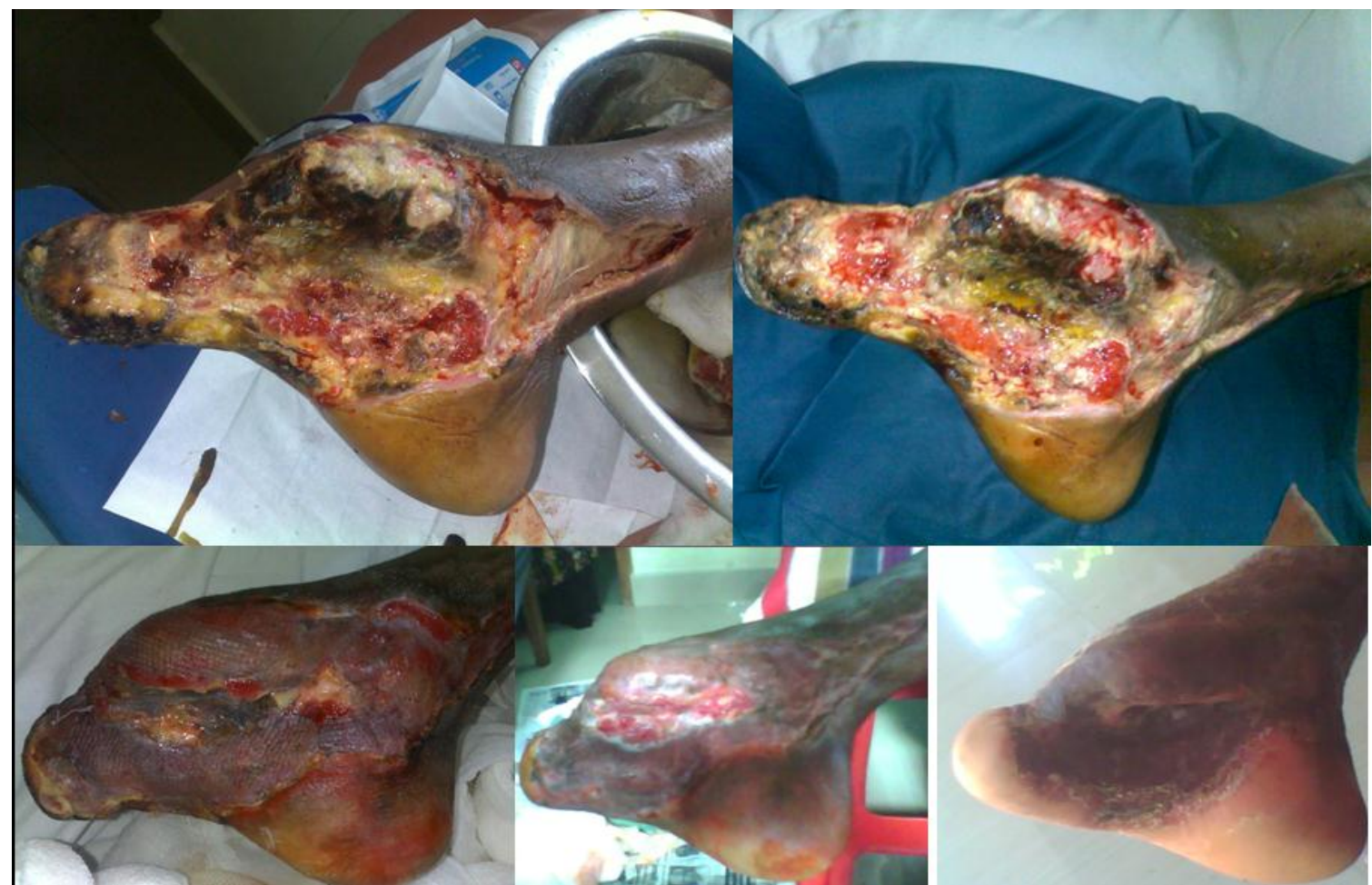

Figure 10 .Diabetic foot infected with Aspergillus niger. Patient received intravenous Amphotericin and serial sugar dressing.There was partial skin graft loss which later covered up.

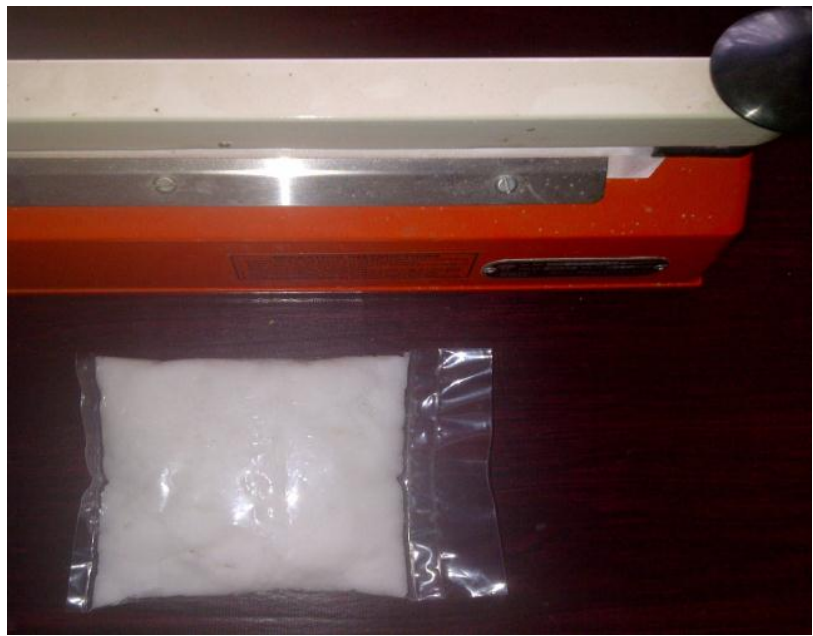

Figure 11 .Packing of sugar dressing material in sealed plastic covers for individual patients .

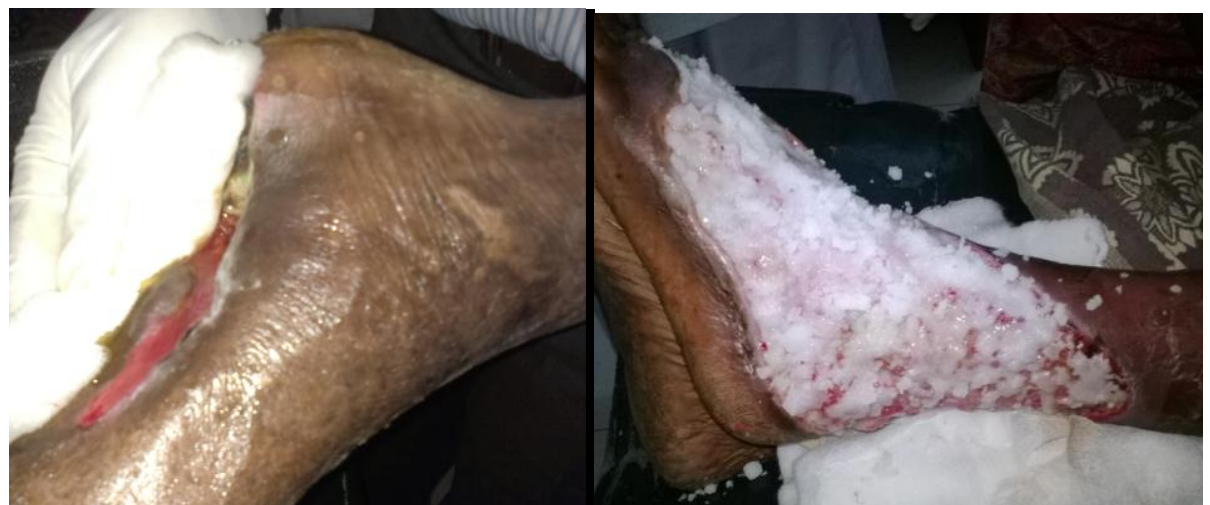

Figure 12. Application of Honey and sugar paste on Wounds which is later padded. 
There was no mortality in our series .All diabetics received insulin for control of blood sugar .The application of either sugar or honey dressing does not affect the glycemic status during our study .Other methods of dressings like Vacuum assisted closure ,application of growth factors were not combined in this comparison trial .However as the slough is cleared rapidly which is the major advantage of sugar dressing can be swicthed over to Vacuum assisted closure or growth factors application or collagen granules to enhance healing . The application of sugar paste does not cause a significant increase in pain when both the groups were compared. However individually some patients with larger area of wound do experience more pain with sugar paste within tolerable limits. As Slough removal was made easy the overall requirement of analgesics will be less as in conventional dressing. Honey attracts ants and sugar dressing paste doesn't and maintenance of the sugar paste was reasonably fair with no additional precautions. Over last few years we have practiced these dressings in our institution with gratifying results. At the end of the study Sugar dressing was found to be better in wound healing compared to Honey dressing in Chronic Wounds.

\section{Conclusion}

Sugar dressing as compared to honey dressing is very effective in wound healing with rapid slough and microbial clearance .The making, storage and application is simple with cost effectiveness and gratifying results.

\section{References}

[1]. Molan PC.Clinical Usage of Honey as wound Dressing.J Wound Care 2004;13(9):353-356

[2]. Dunford C,Hanano R .Acceptability of Honey dressing for non healing Venous leg ulcers.J Wound Care 2004;13 (5):193-7.

[3]. Chirife J,Scarmato GA,Herszage L. Scientific basis for use of granulated sugar in treatment of infected Wounds.Lancet 1982 ;1:560-561

[4]. Scott WJ.Water reactions of staphylococcus aureus at $30{ }^{\circ} \mathrm{C}$.Aust J Biol Sci $1953: 6: 549-552$.

[5]. Kamat N .Use of Sugar in infected Wounds.Trop Doct .1993;23(4):185.

[6]. Archer HG,Brnett S,Irving S,Middleton KR,Seal DV .A controlled model of Moist Wound Healing:Comparison between semipermeable film,antiseptics and sugar paste.J Exp Pathol $1990 ; 71: 155$-170.

[7]. Shetty R ,Sreekar H,Lamba S,Gupta AK.A Novel and accurate technique of photographic wound measurement.Indian J Plast Surg 2012;45:425-9 